\title{
The Case for Pharmacists As Legal Health Care Providers
}

\author{
Erin Albert ${ }^{*}$
}

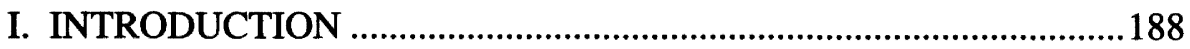

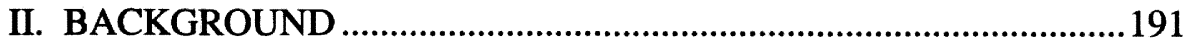

A. The State of Pharmacy Without Provider Status ......................191

B. Legislative History and the Scope of Pharmacy Practice

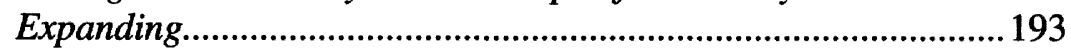

C. Possible Model for Pharmacists to Obtain Provider

Status: The Nurse Practitioner .....................................................195

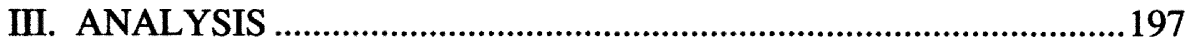

A. Pharmacists Are Already Providing Health Care ...................197

1. Provision of Immunizations ..................................................197

2. Medication Therapy Management (MTM)..........................200

3. The Medical Home and Collaborative

Practice Agreements ...............................................................205

4. Emergency Preparedness and Response...............................207

B. Pros and Cons of Pharmacists as Legal Health

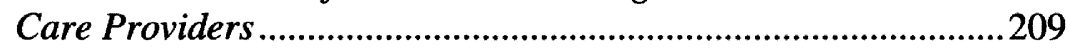

1. Physicians' and Professional Organizations' Opinions

on Pharmacists as Legal Health Care Providers ......................209

2. Pharmacist Professional Societies and Support of

Pharmacists as Legal Providers .................................................211

3. Liability and Provider Status ..............................................212

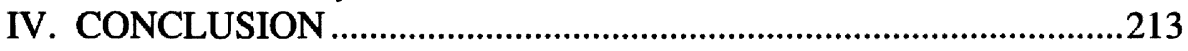

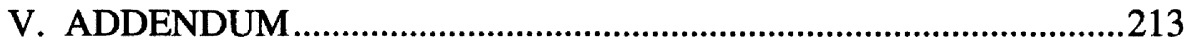

* J.D. Candidate, 2012, Indiana University Robert H. McKinney School of Law; Pharm.D., 2005, Shenandoah University; M.B.A., 2001, Concordia University Wisconsin; B.S., 1994, Butler University, and certified immunizing pharmacist, APhA. The author would like to thank the following for their mentoring assistance on this project: Prof. Joseph L. Fink III, BSPharm., J.D., Michael McMains, R.Ph., Esq., and Prof. Missy Blue, R.Ph, Esq. This Note received the 2011 Indiana State Bar Association Health Law Section's Distinguished Writing Award. 


\section{INTRODUCTION}

The U.S. health care system is broken. The percentage of the uninsured has grown in the United States from 15.6 percent in $2003^{1}$ to 16.7 percent in $2009^{2}$. The number one cause of bankruptcy in the United States, over sixty percent of all bankruptcies in 2007, was medical debt. ${ }^{3}$ According to the World Health Organization's rankings of global health care systems, the U.S. health care system is thirty-seventh overall in terms of performance, while at the same time, it also is the most expensive health care system in the entire world. ${ }^{4}$ In 2005 , researchers calculated that nearly 45,000 Americans aged eighteen to sixty-four died due to a lack of health care insurance. ${ }^{5}$ The total health care expenditure relative to total Gross Domestic Product ("GDP," or $\$ 14.3$ trillion"), according to the Centers for Medicare and Medicaid Services ("CMS") in 2009, was $17.3 \%$, up $1.1 \%$ from the previous year, and the highest annual increase since the year $1960 .^{7}$ Furthermore, the coming tsunami of baby boomers becoming senior citizens will double the elderly population by 2030 , known as the " 2030 problem,", and the country is also potentially facing a 150,000 -physician shortage by $2025 .^{9}$ The American Academy of Family Physicians reports a fifty percent decline in the past decade of medical students entering primary care. ${ }^{10}$ All this seemingly adds up to a daunting environment for Americans

1. Carmen DeNavas-Walt et al., U.S. Census Bureau, Income, Poverty, AND HeAlth InSURANCE CoveraGe IN THE UNITED States: 2003, at 16 (2004), available at http://www.census.gov/prod/2004pubs/p60-226.pdf.

2. Press Release, U.S. Census Bureau, Income, Poverty and Health Insurance Coverage in the United States: 2009 (Sept. 16, 2010), available at http://www.census.gov /newsroom/releases/archives/income_wealth/cb10-144.html.

3. David U. Himmelstein et al., Medical Bankruptcy in the United States, 2007: Results of a National Study, 122 AM. J. MED., 741, 741 (2009).

4. Press Release, World Health Organization, World Health Organization Assesses the World's Health Systems (June 21, 2000), available at http://www.who.int/whr/2000/ media_centre/press_release/en/. See also Sue Stock, Pharmacists Embrace Expanding Medical Role, STANDARD-EXAMINER, Oct. 27, 2010, at 2, http://www.standard.net/topics /medical/2010/10/27/pharmacies-embrace-expanding-medical-role ("A 2007 study from the New England Healthcare Institute estimated that 13 percent of total health care expenditures - more than $\$ 290$ billion a year - arise because people don't take medications as prescribed.").

5. Andrew W. Wilper et al., Health Insurance and Mortality in U.S. Adults, 99 AM. J. Pub. HeAlTh 2289, 2292 (2009).

6. CIA, THE WORLD FACTBOOK, https://www.cia.gov/library/publications/the-worldfactbook/geos/us.html (last modified Nov. 17, 2011).

7. Christopher J. Truffer et al., Health Spending Projections Through 2019: The Recession's Impact Continues, 29 HEALTH AfF. 522, 522 (2010).

8. James R. Knickman \& Emily K. Snell, The 2030 Problem: Caring for Aging Baby Boomers, 37 HEALTH SERVS. RES. 849, 849 (2002).

9. Suzanne Sataline \& Shirley S. Wang, Medical Schools Can't Keep Up, WaLl ST. J. (Apr. 12, 2010), http://online.wsj.com/article/SB10001424052702304506904575180331 528424238.html.

10. Press Release, American Academy of Family Physicians, Fewer Medical Students 
seeking primary care.

However, problems are often disguised as opportunities. One bright spot of hope for health care is that of the profession of pharmacy. In 2009, the Gallup organization's annual Honesty and Ethics poll found pharmacists the second most highly trusted professionals (66\%), only behind nurses $(83 \%){ }^{11}$ Also, pharmacists are the easiest professionals to access within the health care system. ${ }^{12}$ Currently, there are 268,030 pharmacists in the United States, ${ }^{13}$ and the sole degree for entry as of 2004 is a minimum six-year doctor of pharmacy (Pharm.D.) degree. ${ }^{14}$ Pharmacists also have the options of residencies ${ }^{15}$ after their formal educational training, therapeutic specialty board certifications, ${ }^{16}$ and certificates in providing immunizations, ${ }^{17}$ medication therapy management, ${ }^{18}$ diabetes education, ${ }^{19}$ and asthma education. ${ }^{20}$

Choose Family Medicine in 2009 Match (Mar. 19, 2009), available at http://www.aafp.org/online/en/home/publications/news/news-now/resident-student-

focus/20090319match.html. See also Nat'L Ass'N OF ChaIN Drug Stores, Pharmacies: IMPROVING HEALTH, REDUCING COSTS (2010), http://www.nacds.org/user-assets/pdfs/2011/ PrinciplesOfHealthcare.pdf.

11. Lydia Saad, Honesty and Ethics Poll Finds Congress' Image Tarnished, GALluP (Dec. 9, 2009), http://www.gallup.com/poll/124625/Honesty-Ethics-Poll-Finds-CongressImage-Tarnished.aspx.

12. NAT'L Ass'N OF ChaIn Drug Stores, supra note 10. See also Barry L. Carter \& William J. Elliott, Editorial, The Role of Pharmacists in the Detection, Management, and Control of Hypertension: A National Call to Action, 20 PHARMACOTHERAPY 119, 120 (2000) ("The public visits a community pharmacy nearly once a month-more than any other health care facility.").

13. U.S. BUREaU OF LaB. STATistics, OCCUPATION EMP'T \& Wages, MaY 2010: 291051 PHARMACISTS, Table 1, available at http://www.bls.gov/oes/current/oes291051.htm.

14. AcCreditation Council for Pharmacy EdUC., ACCreditation Standards and Guidelines for the Professional Program In Pharmacy Leading to the Doctor OF Pharmacy DegreE: Preamble (Adopted: Jan. 15, 2006), available at http://www.acpeaccredit.org/pdf/ACPE_Revised_PharmD_Standards_Adopted_Jan152006.pdf. See also Jennifer M. Patton et al., AM Last Page: The Doctor of Pharmacy (PharmD) Degree, 85 ACAD. MED. 566, 566 (2010) (Some schools require three pre-professional years before the four-year professional program, and forty-three percent of students entering the professional phase of pharmacy programs already earned a baccalaureate degree.).

15. Directory of Residencies, Fellowships, and Graduate Programs, AM. Coll. OF Clinical PHARMACY, http://www.accp.com/resandfel/ (last visited Sept. 19, 2011).

16. Current Specialties, BD. OF PHARMACY SPECIALTIES, http://www.bpsweb.org/ specialties/specialties.cfm (last visited Dec. 20, 2011).

17. Pharmacy-Based Immunization Delivery, AM. PHARMacists Ass's, https://www. pharmacist.com/AM/Template.cfm?Section=Pharmacy_Based_Immunization_Delivery (last visited Dec. 20, 2011).

18. Training in Medication Therapy Management, AM. PHARMACISTS Ass'N, $\mathrm{http} / / / \mathrm{www} . \mathrm{pharmacist.com} / \mathrm{AM} / \mathrm{Template.cfm}$ ?Section=medication_Therapy_Management _Services_MTMS_(last visited Dec. 19, 2011). See also MTM Central, AM. PhARMACISTS

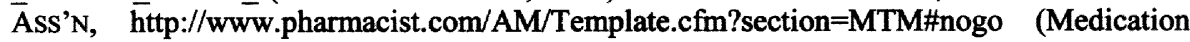
Therapy Management (MTM) has been a service defined as the following, "As defined in a consensus definition adopted by the pharmacy profession in 2004, medication therapy management is a service or group of services that optimize therapeutic outcomes for individual patients. Medication therapy management services include medication therapy reviews, pharmacotherapy consults, anticoagulation management, immunizations, health and wellness programs and many other clinical services. Pharmacists provide medication therapy management to help patients get the best benefits from their medications by actively managing 
"As a result of the evolution in pharmacy education, pharmacists are now trained with a focus and level of expertise in medication therapy management that exceeds any other health care provider's." focus of the profession [of pharmacy] has shifted from quietly dispensing medications to patient-focused practice in which pharmacists discuss with patients how to take their medications, help with medication selection, monitor therapeutic effects and drug-related outcomes, and make medication adjustments. $" 22$

Yet, in the eyes of the law, both at the federal and Indiana state levels, pharmacists are not legally "providers" of health care. Under Title XVIII of the Social Security Act, pharmacists are not included as health care "providers. ${ }^{23}$ Health care providers are also defined under state law. In Indiana, pharmacists are not considered health care providers under the Indiana Medical Malpractice Act. ${ }^{24}$ Although the scope of practice for the pharmacist has potentially widened with the advent of Congress passing the Patient Protection and Affordable Care Act ("PPACA") of $2010^{25}$ along with the Health Care Education and Reconciliation Act ("HCERA") of $2010,{ }^{26}$ the lack of provider status presents several challenges in delivering patient care by pharmacists - namely billing and liability issues.

The objectives of this note are to present evidence and ultimately aver that it is time for pharmacists to be legally considered health care providers both at the federal level under the Social Security Act and at the state level under the Indiana Medical Malpractice Act. The first section provides a background on the current state of pharmacy-including the challenges associated with pharmacists having no provider status, and the history of what has been done to date regarding gaining provider status in other professions, such as nurse practitioners. The second section provides a framework for how pharmacists are in fact already providing health care through programs such as administration of immunizations, providing medication therapy management (MTM), participating in the medical home, and leading emergency preparedness programs. The third section will discuss the pros and

drug therapy and by identifying, preventing and resolving medication-related problems.”).

19. Eligibility Requirements, NAT'L CERTIFICATION BD. FOR DIABETES EdUCATORS http://www.ncbde.org/eligibility.cfm (last visited Sept. 19, 2011).

20. NAT'L ASTHMA EDUCATOR CERTIFICATION BD., http://www.naecb.org/ (last visited Sept. 19, 2011).

21. Jon C. Schommer et al., Pharmacist Contributions to the U.S. Health Care System, 1 INNOVATIONS IN PHARMACY 1, 2 (2010), citing JAMES A. OWEN \& ANNE BURNS, The Pharmacist in Public health: Education, applications, and Opportunities (2010).

22. Marie A. Chisholm-Burns et al., Pharmacy Management, Leadership, MARKETING, AND FINANCE 50 (Marie A. Chisholm-Burns et al. eds., 1st ed. 2011).

23. 42 U.S.C. $\$ 1395(2011)$.

24. IND. CoDE § 34-18-2-14 (2011).

25. Patient Protection and Affordable Care Act, Pub. L. No. 111-148, 124 Stat. 119 through 1025 (2010).

26. Health Care and Education Reconciliation Act of 2010, Pub. L. No. 111-152, 124 Stat. 1029 through 1084 (2010). 
cons of achieving provider status as pharmacists and will explore different stakeholder interests and positions of pharmacists increasing their scope of care.

\section{BACKGROUND}

\section{A. The State of Pharmacy Without Provider Status}

Pharmacists without legal provider status are presented with two equally precarious issues: (1) a lack of priority in reimbursement from third party payers for selling their products and services and (2) increased potential risk of liability while not possessing provider status under the Indiana Medical Malpractice Act. The first problem is best demonstrated by a recent true story of Tom Miller, an Illinois independent pharmacist and pharmacy owner of Miller's Pharmacy in rural Marion, Illinois. ${ }^{27}$ On July 19, 2010, Mr. Miller not only had to close his pharmacy, but he also had to file bankruptcy for his pharmacy business. ${ }^{28} \mathrm{He}$ also may have to file bankruptcy personally because he took out personal loans for the business to keep the pharmacy running. ${ }^{29}$ While a notable recession is occurring in Illinois and around the country, the reason for Mr. Miller's demise was courtesy of the State of Illinois reimbursing him as a third party payer for his Medicaid patients. $^{30}$ Because the majority of Mr. Miller's patients were Medicaid recipients, he relied upon the State to reimburse him in a timely fashionideally within forty-five days. ${ }^{31}$ However, his payments were taking much longer to arrive. In fact, the State of Illinois takes an average of 153 days to reimburse pharmacists. "While the stimulus package ${ }^{33}$ requires states to pay other health care providers quickly, it has no such protections for pharmacies." ${ }^{34}$ As a result, independent and other rural pharmacies like $\mathrm{Mr}$. Miller's who have a large Medicaid patient population are either closing their doors and laying off their employees, or worse for patients, no longer accepting patients who have Medicaid as their third party insurance payer. ${ }^{35}$ This is an example of the problem for pharmacists who do not have provider status and the damage it can do to pharmacists and their patients.

This story represents the plight of the pharmacist when billing and suf-

27. Daniel C. Vock, In Illinois, Late Payments Fray the Safety Net, STATELINE (Oct. 19, 2010), http://www.stateline.org/live/details/story?contentId=521562.

28. Id.

29. Id.

30. Id.

31. Id.

32. Id.

33. American Recovery and Reinvestment Act of 2009, Pub. L. No. 111-5, 123 Stat. 115 (2010).

34. Vock, supra note 27.

35. Id. 
fering from a lack of status as a legal health care provider. While the Medicare Prescription Drug, Improvement, and Modernization Act of $2003^{36}$ provided pharmacists the opportunity for the first time ever to bill for Medication Therapy Management services, by providing independent billing codes (named Current Procedural Technology or CPT codes) to perform clinical medication therapy review services under Medicare Part D, insurance companies and third party payers, including the federal government, nonetheless rely upon the provider status definition of Medicare Part B to discern who can be paid directly for their services (legal providers), and who is paid indirectly incident to physician providers (not legal providers). ${ }^{37}$ Pharmacists struggle to bill for their services directly and independently. Says one Indiana clinical pharmacist, "This limited billing ability prevents pharmacists from being hired at physician offices, since they cannot earn their salary with reimbursement from patient services alone."38 Therefore, while the federal government has opened the door to pharmacists being potentially reimbursed for providing cognitive services, the lack of legal provider status limits the methods and levels of reimbursement. "A major priority ... is to foster expanded patient access to the clinical services of pharmacists. One of the most important tactics for achieving this objective is to obtain, incrementally, payer-specific provider status for pharmacists." ${ }^{\text {"9 }}$ Pharmacists currently do not have independent, legal provider status; provider status is critical to obtain, because status is also linked to reimbursement and payment.

The second major challenge for pharmacists, after billing and reimbursement in Indiana, is that of a lack of protection for pharmacists as providers under the Indiana Medical Malpractice Act. Indiana Code Section 34-18-2-14, or the Medical Malpractice Act of 1975, was established to decrease "exposure to malpractice claims and lessen the alleged difficulty of obtaining malpractice insurance" for health care providers. ${ }^{40}$ In Kroger Co. v. Estate of Hinders, the Indiana Court of Appeals held that pharmacists were not providers in Indiana, and furthermore, "the [Indiana Medical Malpractice statutes] clearly do not protect pharmacists and pharmacies.",11

36. Pub. L. No. 108-173, 117 Stat. 2066 (2003).

37. Am. Pharmacists Ass'N, Billing for MTM Services: Tips for Pharmacists (2008), available at $\mathrm{http}: / / \mathrm{www}$.pharmacist.com/AM/TemplateRedirect.cfm?template $=/ \mathrm{CM} /$ ContentDisplay.cfm\&ContentID $=24120$.

38. E-mail from Emily Papineau, Assistant Professor of Pharmacy, Butler University, to Erin Albert, Assistant Professor of Pharmacy, Butler University (July 26, 2010, 04:07 EST) (on file with author).

39. Lisa Daigle \& David Chen, ASHP Policy Analysis: Pharmacist Provider Status in 11 State Health Programs, AM. Soc'y Health-SyS. PhaRmacists (2008), available at http://www.ashp.org/DocLibrary/Advocacy/ProviderStatusPrograms.asp.

40. Kroger Co. v. Estate of Hinders, 773 N.E.2d 303, 307 (Ind. Ct. App. 2002). See also Winona Mem. Found. v. Lomax, 465 N.E.2d 731 (Ind. Ct. App. 1984); see also Warrick Hosp. v. Wallace, 435 N.E.2d 263 (Ind. Ct. App. 1982).

41. Kroger Co., 773 N.E.2d at 307. 
Lastly, under Indiana Code Section 34-11-2-3, there is a two-year statute of limitations for tort claims against "physicians, dentists, surgeons, hospitals, sanitariums, or others." However, the Kroger court stated that this law did not apply because pharmacists are not included in this definition, nor are they included as "others." 43 Thus, the second challenge in lack of provider status in Indiana opens the pharmacist up to potentially wider liability because pharmacists have no protection under the Indiana Medical Malpractice Act. Other states have also concluded that pharmacies are not covered under similar medical professional liability acts. For example, in Phillips v. Larry's Drive-In Pharmacy, Inc., the West Virginia Supreme Court overturned the lower circuit court's holding that a pharmacy was included as a health care provider ${ }^{44}$ under the West Virginia Medical Professional Liability Act; ${ }^{45}$ thus, the limits enjoyed by health care providers under the act were not included for pharmacies.

\section{B. Legislative History and the Scope of Pharmacy Practice Expanding}

Because of these challenges, and as the scope of the practice of pharmacy has evolved, so has the movement to gain legal provider status among the profession. In the $1960 \mathrm{~s}$, the role of the clinical pharmacist, particularly in hospitals, became the genesis of clinical practice. ${ }^{46}$ In 1976, the Board of Pharmaceutical Specialties ("BPS") was established to recognize and develop board certifications for pharmacists. ${ }^{47}$ During 1988 , eighty percent of state statutes contained some form of definition of pharmacy practice. ${ }^{48}$ In 1990, the federal Omnibus Budget Reconciliation Act ${ }^{49}$ was passed, requiring pharmacists to counsel patients and perform drug utilization review ("DUR"), a review of all of a patient's medications. ${ }^{50}$ Also, the National Association of Boards of Pharmacy ("NABP") developed a Model State Pharmacy Act, along with Model Rules, including a definition of the practice of pharmacy, which is the following:

The "Practice of Pharmacy" means the interpretation,

42. IND. CODE § 34-11-2-3 (2010).

43. Kroger Co., 773 N.E.2d at 308.

44. Phillips v. Larry's Drive-In Pharmacy, Inc., 647 S.E.2d 920 (2007). See also Joseph L. Fink III, Is a Pharmacy a "Health Care Provider"?, PhaRMACY TIMES, Dec. 2007 , at 46 .

45. W.Va. Code $\S \S 55-7 \mathrm{~B}-2-(\mathrm{g})(2011)$.

46. Henri R. Manasse, Jr. \& Marilyn K. Speedie, Pharmacists, pharmaceuticals, and policy issues shaping the work force in pharmacy, 64 AM. J. HEALTH-SYS. PHARMACISTS e30, e33 (2007).

47. Johanna L. Keely, Position Paper: Pharmacist Scope of Practice, 136 ANN. INTERN. MED. 79 (2002).

48. Manasse, Jr. \& Speedie, supra note 46, at e34.

49. Pub. L. No. 101-508, 104 Stat. 1388 (2010).

50. Manasse, Jr. \& Speedie, supra note 46, at e34. 
evaluation, and implementation of Medical Orders; the Dispensing of Prescription Drug Orders; participation in Drug and Device selection; Drug Administration; Drug Utilization Review (DUR); the Practice of Telepharmacy within and across state lines; Drug or Drug-related research; the provision of Patient Counseling; the provision of those acts or services necessary to provide Pharmacist Care in all areas of patient care, including Primary Care, Medication Therapy Management, Collaborative Pharmacy Practice, the ordering, conducting, and interpretation of appropriate tests, and the recommendation and administration of immunizations; and the responsibility for Compounding and Labeling of Drugs and Devices ...., proper and safe storage of Drugs and Devices, and maintenance of required records. ${ }^{51}$

Two key watershed events occurred in 1994 relative to pharmacists and administration of immunizations: (1) Secretary Donna Shalala of the U.S. Department of Health and Human Services ("HHS") asked the American Pharmacists Association ("APhA") to develop the role of pharmacy in immunizations for children, ${ }^{52}$ and (2) the Washington State Pharmacy Association teamed up with Georgia pharmacist, entrepreneur, and pioneer of providing vaccines in community practice, Michael Reagan, to provide the first organized vaccine administration training program for pharmacists in Seattle. ${ }^{53}$ In 1995, two pharmacists went to local physicians in Washington State and contracted into collaborative practice agreements ("CPAs") in order to administer influenza vaccines. ${ }^{54}$ In 2001, two pharmacist organizations (the American Society of Health-System Pharmacists ("ASHP") and the American College of Clinical Pharmacy ("ACCP")) joined forces to work on the provider movement, ${ }^{55}$ and in 2002, a group of pharmacy organizations formed the Pharmacist Provider Coalition, with the "goal of achiev-

51. Nat'l Ass'n of Bds. of Pharmacy, Model State Pharmacy Act and Model Rules of the National Association of Boards of Pharmacy $\S 104$ (August 2011), available at http://www.nabp.net/publications/assets/ModelAct.doc.

52. Michael D. Hogue et al., Pharmacist Involvement with Immunizations: A Decade of Professional Advancement, 46 J. AM. PHARMACISTS Ass'N 168, 169 (2006).

53. Id. at 170.

54. Id. at 169. See also L.A. Ferro et al., Collaborative practice agreements between pharmacists and physicians, 38 J. AM. PHARMACISTS ASS'N 655, 655 (1998) (A collaborative practice agreement between pharmacists and physicians "enable[s] pharmacists to monitor and manage a patient's drug therapy, usually within the parameters of an agreed-upon treatment protocol.").

55. Press Release, Medscape Today, Provider Status for Pharmacists Needed, Alliance Says, Medscape Medical News (Apr. 5, 2001), available at http://www.medscape.com/viewarticle/411270. 
ing recognition and payment for pharmacist services under Part B of the Medicare program." ${ }^{\text {In }}$ In 2003, the Medicare Prescription Drug, Improvement, and Modernization Act ${ }^{57}$ ("MMA") was passed by Congress to add a drug benefit to Medicare recipients, Medicare Part D. ${ }^{58}$ Unfortunately, while MMA did provide pharmacists the codes to bill for cognitive services, it did not recognize pharmacists as legal providers of health care under Part B. Representative Richard Burr of North Carolina introduced the Medicare Clinical Pharmacist Practitioner Services Coverage Act of 2004; ${ }^{59}$ however, it never passed. ${ }^{60}$ The American Recovery and Reinvestment Act of 2009 included in Title XXX under Health Information Technology and Quality, included pharmacists and pharmacies as health care providers. ${ }^{61}$ In 2010, the Patient Protection and Affordable Care Act passed, and it encouraged primary care practice in the form of medical homes, and the independence at home medical practice included physicians, nurses, physician assistants and pharmacists, among others, to provide home-based primary care services. ${ }^{62}$ The movement forward towards pharmacists as providers under the Social Security Act has been decades in the making; however, it remains elusive. Provider status is important, as it is the standard by which insurance carriers and third parties identify as professionals who can be reimbursed directly at the federal level and who can be protected by malpractice limits from tort actions under medical malpractice acts at the state level.

\section{Possible Model for Pharmacists to Obtain Provider Status: The Nurse Practitioner}

The elusive provider status has been achieved by other professions, namely nursing. Nurse practitioners gained provider status under the Balanced Budget Act of $1997,{ }^{63}$ but this did not come overnight; it took several decades of diligence, evolution of the profession, and lobbying before provider status became a reality;

[t] he key strategies that contributed to this victory were (1) gaining recognition that nursing had the potential to expand its role, (2) documenting nurse prac-

56. Manasse, Jr. \& Speedie, supra note 46 , at e35.

57. Pub. L. No. 101-508, 104 Stat. 1388 (2010).

58. CTr. For MedicARE \& MedicAid Servs. (CMS), OVERVIEW: Prescription DRUG COVERAGE - GENERAL INFORMATION, available at http://www.cms.gov/PrescriptionDrug CovGenIn/01_Overview.asp.

59. H.R. 4724, 108th Cong. (2004).

60. Manasse, Jr. \& Speedie, supra note 46, at e35.

61. American Recovery and Reinvestment Act of 2009, Pub. L. No. 111-5 (2009).

62. Patient Protection and Affordable Care Act, Pub. L. No. 111-148, 124 Stat. 119 through 1025 (2010) (emphasis added).

63. Balanced Budget Act of 1997. Pub. L. 105-33, 111 Stat. 296. 
titioners value, (3) establishing standards in education and credentialing, (4) using professional organizations to empower individuals, and (5) being willing to accept small, incremental gains over time. ${ }^{64}$

The first nurse practitioner training program began in 1965 , due to the shortage of physicians and primary care services. ${ }^{65}$ Despite pushback from physician groups, the nurse practitioners supported their role with evidencebased medicine, research, publications, and cost-effective delivery of primary care. ${ }^{66}$ Voluntary certifications then evolved for the nurse practitioner, along with advanced education. ${ }^{67}$ In 1977, the Rural Health Clinic Act gave some nurse practitioners reimbursement if they were serving rural areas, and it mandated fifty percent of funded rural health services be provided "by nurse practitioners, certified nurse-midwives, and physician assistants. ${ }^{\prime 68}$ This practice settings' data was then leveraged to demonstrate to managed care and third party payers that the services were cost effective; but then the nurse practitioners realized that they would need to begin an aggressive lobbying campaign, which would last for twenty years, in order to gain provider status. ${ }^{69}$ They encouraged and had nurses in key policy and fellowship positions in order to increase their presence on Capitol Hill, established positions on a Physician Payment Review Committee, and trained nurses to communicate with policy- and law-makers as health care professionals. ${ }^{70}$ This work culminated in a leadership summit in 1993 and a published position statement, along with formation of the National Nurse Practitioner Coalition ("NNPC"), a lobbying group. ${ }^{71}$ This lobbying group morphed into the American College of Nurse Practitioners ("ACNP"), and ACNP members barraged their federal representatives with "calls, faxes, emails that applied the pressure on Congress to get the job done."72

64. John M. O'Brien, How Nurse Practitioners Obtained Provider Status: Lessons for Pharmacists, 60 AM. J. HEALTH-SYS. PhARMACISTS 1, 1 (2003), available at http://www. medscape.com/viewarticle/464663_print.

65. Id. at 2.

66. Id.

67. Id.

68. Id. at 3-4. See also Rural Health Clinic Act of 1977, Pub. L. No. 95-210.

69. O'Brien, supra note 64, at 3.

70. Id. at 5 .

71. Id. at 2.

72. Press Release, American College of Nurse Practitioners, Nurse Practitioners Victorious in Budget Bill, ACNP Grassroots Effort Pays Off (Aug. 13, 1997), available at http://www.acnpweb.org/i4a/pages/index.cfm?pageid=3357. 


\section{ANALYSIS}

\section{A. Pharmacists Are Already Providing Health Care}

In reality, pharmacists are in fact already providers of health care. Through the evolution of the education of a pharmacist from a four-year professional degree to a rigorous six-year doctor of pharmacy degree), to residencies, board certifications, and therapeutic and professional continuing professional development certifications, pharmacists have been widening their scope of practice in order to meet the challenges of primary care, immunizations, public health, rural health, and indigent population health by stepping up to the plate and providing services to these professional areas and populations. There are four general areas to be explored relative to pharmacists providing health care in the United States that support and demonstrate the need for provider status of pharmacists: administration of immunizations; providing medication therapy management ("MTM"); supporting and practicing within the medical home as part of the health care provider team, and with that, contracting with physicians under collaborative practice agreements; and providing health care when and if disaster strikes under emergency preparedness.

\section{Provision of Immunizations}

On average, 36,000 people die needlessly from influenza complications or the seasonal flu each year; of those, ninety percent are people aged sixty-five and older. ${ }^{73}$ In adults, diseases such as Tetanus, Diphtheria, Pertussis, Measles, Mumps, Rubella, Varicella, Pneumococcal diseases, Hepatitis $\mathrm{A}$ and B, Meningococcal diseases, Herpes zoster, and Human Papillomavirus ("HPV") can all be prevented with vaccines (also known as vaccine-preventable diseases, or "VPDs"). ${ }^{74}$ The U.S. Adult Immunization Schedule strongly suggests fourteen vaccinations for adults against infectious diseases. ${ }^{75}$ While childhood immunizations are at all-time highs, the opposite is true of adult immunizations, with only seventy percent of adults

73. NAT'L Found. For INFECTIOUS Diseases, FaCts ABout AdULt IMMUNIZATION, available at $\mathrm{http}: / / \mathrm{www}$.nfid.org/pdf/factsheets/adultfact.pdf.

74. Karen K. O'Brien, Pharmacists' Role in Preventing Vaccine-Preventable Diseases, 34 U.S. PHARMACIST 39 (2009), available at http://www.uspharmacist.com/content/d/ feature/i/783/c/14501\%. See also CTRS. For Disease CONTROL \& PREVENTION, ADVISORY COMMITTEE ON IMMUNIZATION PRACTICES (ACIP), RECOMMENDATIONS, available at http://www.cdc.gov/vaccines/recs/acip/default.htm.

75. THe Nat'l Found. FOR INFectious Diseases, National SuRvey on AdUlt VACCINATION REPORTS LOW CONSUMER AWARENESS OF VACCINES AND THE RISKS OF VACCINE-PREVENTABLE DISEASES, available at http://www.nfid.org/pdf/factsheets /survey.pdf. 
obtaining the influenza vaccination. ${ }^{76}$ Barriers to receiving a vaccine in a survey by the National Foundation for Infectious Diseases included adults reporting being too busy to get a vaccine $(13 \%)$, believing vaccines do not work $(14 \%)$, reporting they would not obtain a vaccine because they had to pay for it $(22 \%)$, reporting vaccines are too expensive to obtain $(26 \%)$, and reporting that vaccines are not safe $(35 \%){ }^{77}$ Furthermore, there are significant costs-indirect and direct-associated with infectious disease. For example, a global resurgence of measles from 1989-91 occurred, "resulting in more than 55,000 cases, 11,000 hospitalizations, 120 deaths, and $\$ 100$ million in direct medical care costs.",78

Since the first vaccination procedure in 1796 by Edward Jenner, ${ }^{79}$ pharmacists have been working with and supporting vaccination campaigns. Pharmacists not only dispense vaccinations, but they can also educate in order to eradicate most if not all of the barriers that adult patients perceive with vaccinations. The expansion of pharmacists administering vaccines came in 1994 when the first vaccination training program was offered to pharmacists. $^{80}$ By 2008 , over 30,000 pharmacists had been formally trained on how to administer vaccinations, ${ }^{81}$ and as of October 2010 , the number of pharmacists who had completed the American Pharmacists Association certificate training program on Pharmacy-Based Immunization Delivery was $140,000,{ }^{82}$ or over $60 \%$ of the 220,000 licensed pharmacists in the United States. ${ }^{83}$ Pharmacists in all fifty states had some legal capacity to provide vaccinations as of September 12,$2009 ; ;^{84}$ although, there is wide variability as to whom pharmacists may vaccinate, such as adults, but not children, and under a prescription, under a protocol without, or all of the above. ${ }^{85}$ Viewing the most recent pandemic, or potential pandemic - the 2009 H1N1 Influenza outbreak-writers of, The 2009 H1N1 Influenza Vaccination

76. Alan R. Hinman and Walter A. Orenstein, Adult Immunization: What Can We Learn from the Childhood Immunization Program?, 44 CLINICAL INFECTIOUS DisEASES 1532, 1532, available at http://cid.oxfordjournals.org/content/44/12/1532.full.

77. THE NAT'L FOUND. FOR INFECTIOUS DISEASES, supra note 75, at 2.

78. Ctrs. for Disease Control \& Prevention, Healthy People 2010: 14 : IMMUNIZATION AND INFECTIONS DISEASES, 1, 4, available at http://www.healthypeople.gov/ document/html/volume1/14immunization.htm.

79. Hogue et al., supra note 52, at 169.

80. Id.

81. O'Brien, supra note 74 , at 41 .

82. E-mail from Misty L. Robling, Certificate Program Coordinator, American Pharmacists Association, to Erin Albert, Assistant Professor of Pharmacy, Butler University (Oct. $28,2010,10: 41$ EST) (on file with author).

83. O'Brien, supra note 74, at 41 (The percentage calculation in this sentence is based upon 220,000 licensed pharmacists in the U.S. The actual percentage is $63.63 \%$ as of Oct. 28, 2010.).

84. Kate Traynor, With Maine on Board, Pharmacists in All 50 States Can Vaccinate, AM. SoC'y Health-SyS. PhaRmaCISTS (Nov. 1, 2009), http://www.ashp.org/menu/News/ PharmacyNews/NewsArticle.aspx?id=3199 (last visited Oct. 30, 2010).

85. Id. See also O'Brien, supra note 74, at 41 . 
Campaign: Summary of a Workshop Series, Clare Stroud and others, stated the following regarding pharmacies:

\begin{abstract}
Many arguments can be given for the use of retail pharmacies in administering vaccine, but the most compelling is availability; large numbers of immunizers are ready and available to administer vaccine. For example, Walgreens, as of the time of the workshops, had trained 85 percent of its pharmacists as immunizers, with a goal to increase that to 100 percent. Pharmacies know their markets; they are in the community and have established relationships with local, state, and national public health. Distribution networks are already in place and easily accessed by high-risk individuals. Also, pharmacies are open during evening, weekend, and holiday hours, when public health clinics and doctors' offices may be closed. Retail clinics located inside pharmacies also provided $2009 \mathrm{H} 1 \mathrm{~N} 1$ vaccinations . . . . Opening up vaccination through retail pharmacies increases the number of access points the population has to receive vaccine. $^{86}$
\end{abstract}

The story of Patti Veliotes is a final, real-world example of why pharmacists are immunizing patients, preventing illness, and already providing health care. ${ }^{87}$ Patti, a seventy-six-year-old woman, had friends who were getting shingles, and she wanted to get an immunization to prevent shingles in herself. ${ }^{88}$ She went to her doctor to obtain one, but her doctor did not have the vaccine in his office. ${ }^{89}$ Why? Two reasons: (1) the shingles vaccine must be stored frozen, and (2) because, "Increasingly, doctors are opting not to provide these vaccines because reimbursement from private insurance and Medicare is often inadequate." 90 Dr. Kenneth Schmader, chief of geriatric medicine at Duke University Medical School, goes on to state in regard to pharmacists providing immunizations the following: "I think it's a good idea from a public health perspective .... We try to remove as many barriers as we can to vaccination; having as many

86. Clare Stroud et al., The 2009 HiN1 Influenza Vaccination Campaign: SUMMARY OF A WORKSHOP SERIES 44-45 (2009), available at http://www.nap.edu/catalog/ 12992.html.

87. Patti Neighmond, Many Pharmacists Now Administer Vaccinations, NAT'L PUB. RADIO (Oct. 18, 2007), http://www.npr.org/templates/story/story.php?storyld=15380907.

88. Id.

89. Id.

90. Id. 
providers as possible to give a vaccine is a good thing, and that includes pharmacists. "91 If doctors who are legal providers of health care opt out of offering their patients health care in the form of immunizations, who will step up and offer them instead? Pharmacists. If pharmacists are willing to provide this care, they should be legal providers as well, and should be reimbursed at levels of other legal providers of health care.

\section{Medication Therapy Management (MTM)}

Under MMA of 2003, PPACA of 2010, and HCERA of 2010, pharmacists are given larger opportunities and potential responsibilities to perform drug optimization management in the form of medication therapy management, or MTM. MTM is:

As defined in a consensus definition adopted by the pharmacy profession in 2004, medication therapy management is a service or group of services that optimize therapeutic outcomes for individual patients. Medication therapy management services include mediation therapy reviews, pharmacotherapy consults, anticoagulation management, immunizations, health and wellness programs and many other clinical services. Pharmacists provide medication therapy management to help patients get the best benefits from their medications by actively managing drug therapy and by identifying, preventing and resolving medication-related problems. ${ }^{92}$

Through the MMA of 2003, CMS required each health insurance company providing Medicare Part D plans with drug coverage to also provide MTM services for eligible patients, ${ }^{93}$ which must include the ability to "optimize therapeutic outcomes through improved medication use and reduce the risk of adverse events, including adverse drug reactions." 94 While other health care providers could deliver these services, only pharmacists

91. Id. (emphasis added).

92. AM. PHARMACISTS Ass'N, supra note 18.

93. Djenane Ramalho de Oliveira et al., Medication Therapy Management: 10 Years of Experience in a Large Integrated Health Care System, 16 J. MANAGED CARE PHARMACY 185, 186 (2010), available at http://www.cms.gov/prescriptiondrugcovContra/082_mtm.asp (quoting Medicare Part $D$ Medication Therapy Management (MTM) Programs, $\overline{\mathrm{C}}_{\mathrm{TRS}}$. FOR MEDICARE AND MEDICAID SERVS. (2010), available at http://www.cms.gov/prescription drugcovcontra/082_mtm.asp).

94. Id. (quoting Medicare Part D Medication Therapy Management (MTM) Programs, CTRS. FOR MEDICARE AND MEDICAID SERVS. (2010), available at http:// Www.cms.gov/prescriptiondrugcovcontra/082_mtm.asp). 
were specifically mentioned as providers of these services. ${ }^{95}$ MTM services can also vary from pharmacy to pharmacy, can be targeted for specific disease management states, such as diabetes, and can be described as pharmaceutical care, ${ }^{96}$ and can include even brown bag sessions, where patients bring all of their medications to one pharmacist for review live or telephonically. ${ }^{97}$ Providing this service allows a pharmacy to expand its pharmacists' scope of practice and "to be reimbursed for direct patient care services. ${ }^{98}$ However, pharmacists were already previously providing various forms of MTM services prior to MMA 2003. The classic MTM experiment, and one of the first to the pharmacy world, occurred in Asheville, North Carolina, and is otherwise know as the Asheville Project. The Asheville project was a collaborative MTM program dealing with two specific disease states-diabetes mellitus ${ }^{99}$ and asthma. ${ }^{100}$ This was a collaborative project for the employees of the city of Asheville. Asheville was a selfinsured entity, covering 1030 patients within its plan. ${ }^{101}$ The city identified sixty city employees or dependents who suffered from diabetes. ${ }^{102}$ To those diabetic patients, the city offered an opportunity: if they would agree to see a pharmacist to learn how to better manage their disease, they would receive a waiver of their co-pays on drugs and supplies for monitoring diabetes as an extra incentive to enroll in this project. ${ }^{103}$. Furthermore, the City of Asheville paid pharmacists for their time while consulting these patients$\$ 75$ for an initial consultation, $\$ 45-65$ for intermediate assessments lasting 30-45 minutes, and $\$ 20$ for follow-up visits. ${ }^{104}$ The total cost of the program, including compensation for the pharmacists, was around $\$ 14,000$ for the city. ${ }^{105}$ The director of risk management for the city saw positive outcomes as early as six months into the program. ${ }^{106}$ Patients were taking bet-

95. Id.

96. Id.

97. See generally Alan Nathan et al., 'Brown Bag' Medication Reviews as a Means of Optimizing Patients' Use of Medication and of Identifying Potential Clinical Problems, 16 FAM. PraC. 278 (1999).

98. Ramalho de Oliveira et al., supra note 93.

99. Daniel G. Garrett, The Answer to How Is When: The Genesis of the Asheville Project, Pharmacy TIMEs, Oct. 1998, at 4, available at http://www.pharmacytimes.com/files/ articlefiles/TheAshevilleProject.pdf.

100. Barry A. Bunting \& Carole W. Cranor, The Asheville Project: Long-Term Clinical, Humanistic and Economic Outcomes of a Community-Based Medication Therapy Management Program for Asthma, 46 J. AM. PhARMACISTS Ass'N 133 (2006).

101. John Miall, Jr., An Investment in Health Offers a High Return for All, PHARMACY TIMES, Oct. 1998, at 28, available at $\mathrm{http} / / \mathrm{www}$.pharmacytimes.com/files/articlefiles/ TheAshevilleProject.pdf.

102. Id.

103. Id.

104. Id. at 29.

105. Id.

106. Id. 
ter care of themselves, according to the plan nurse. ${ }^{107}$ The primary measurement, control of hemoglobin A1C for diabetic patients, showed that eighty-five percent of the patient population in the program at fourteen months had at least some improvement. ${ }^{108}$ Also, insurance claims on inpatient and outpatient services decreased by $\$ 20,246$ during the one-year treatment period, despite compensating pharmacists for their time in providing cognitive services. ${ }^{109}$ Said one endocrinologist of the program:

A chronic illness like diabetes requires a lot of self-
management. Pharmacists educated and trained to
assist in the management of that specific health prob-
lem can make a difference by monitoring people with
diabetes and encouraging them to follow through on
self-care and with other providers .... This type of
program works best as a team effort, with primary
care physicians, endocrinologists, pharmacists, educa-
tors, case managers, data managers, and hospital ad-
ministrators working together.

An asthma program yielded similar positive results as part of the Asheville Project. ${ }^{111}$ Therapeutic outcomes in forced expiratory volumes ("FEV ") improved and were sustained, 99\% of patients had an asthma action plan, emergency department visits decreased from nearly $10 \%$ to $1.3 \%$, hospitalizations due to asthma decreased, and both indirect cost savings of $\$ 1230 /$ patient/year and direct cost savings of $\$ 725 /$ patient/year were realized over the course of the 5-year study. ${ }^{112}$ Interestingly, patients at baseline who were seeing a primary care doctor had a severity score of 3.3 on a 4-point severity scale, and those seeing a specialist had a baseline score of 3.0 , but both groups improved their severity scores down to a 2.5 , and both were statistically significant from baseline. ${ }^{113}$ This result demonstrates that pharmacist education and intervention, regardless of whether the patient was seeing a primary care provider or a specialist, provided a benefit to the patient through pharmaceutical care or MTM by the pharmacist.

107. Id.

108. Carole W. Cranor, Outcomes of the Asheville Diabetes Care Project, PHARMACY TIMES, Oct. 1998, at 19, 21, available at http://www.pharmacytimes.com/files/articlefiles/ TheAshevilleProject.pdf.

109. Id. at 19, 22.

110. Paul Martin, Working Together to Improve Patient Care, PHARMACY Times, Oct. 1998, at 26, available at http://www.pharmacytimes.com/files/articlefiles/TheAshevilleProject.pdf.

111. Bunting \& Cranor, supra note 100.

112. Id.

113. Id. at 138 (The authors of this paper did not state there was equal benefit relative to the outcome of the 4-point severity scale in this paper; they merely presented the data.). 
There are other studies that demonstrate economic, therapeutic, and patient satisfaction and outcome data supporting the idea that what pharmacists do in MTM makes a significant difference in the lives of patients. The Diabetes Ten City Challenge reduced total health care costs by $\$ 1079$ per patient per year compared to projected costs using community-based pharmacist disease state coaching. ${ }^{114}$ Hemoglobin A1C had statistically significant decreases for the managed patient population, along with statistically significant, clinically positive outcomes on decreasing LDL cholesterol and systolic blood pressure. ${ }^{115}$ Influenza vaccination rates in the patient population doubled, foot examinations more than doubled, and eye examinations increased from fifty-seven percent to eighty-one percent. ${ }^{116}$

Pharmacists are already providing health care services through MTM. Some of the challenges moving forward, while considering the former challenges faced by nurse practitioners gaining provider status, include the following for the profession of pharmacy to consider: (1) standardizing quality and consistency, through MTM certification and training programs; (2) harmonizing billing platforms and health care information technology (HIT) standards; and (3) consistently demonstrating value - both clinical and economic - of MTM services to the public and other health care partners. The American Pharmacists Association along with eighteen additional organizations are already providing MTM certification programs as continuing professional development for pharmacists. ${ }^{117}$ This allows for efficient and effective training standards for the profession relative to MTM. ${ }^{118}$ Second, there are currently thirty U.S. health care insurance plans that support pharmacists providing MTM services. ${ }^{119}$ Several information technology platforms by which pharmacists may bill for MTM services also exist-Outcomes, Nexdose, Medication Pathfinder, Medication Management Systems, Inc., Community MTM, Clinical Support Services, ${ }^{120}$ and Mirixa ${ }^{121}$ to name a few. Outcomes, one of the platforms, reported finding over one million medication therapy problems alone through its Targeted

114. Toni Fera et al., Diabetes Ten City Challenge: Final economic and clinical results, 49 J. AM. PHARMACISTS Ass'N 383, 383 (2009).

115. Id.

116. Id.

117. Harold N. Godwin, President, Am. Pharmacists Ass'n, Inaugural Speech at the Annual Meeting: Setting the Vision for a Stronger Tomorrow (Mar. 14, 2000) (transcript available at http://www.pharmacist.com/AM/Template.cfm?Section=MTM\&CONTENTID= 23153\&TEMPLATE $=/ \mathrm{CM} /$ ContentDisplay.cfm).

118. Delivering Medication Therapy Management Services in the Community, AM. PHARMACISTS Ass'N, http://www.pharmacist.com/AM/Template.cfm?Section =Delivering_Medication_Therapy_Management_in_the_Community (last visited Dec. 25, 2011).

119. Godwin, supra note 117

120. Pharmacy Marketplace, MTM (Medication Therapy Management), PHARMACY CHOICE, http://www.pharmacychoice.com/marketplace/category.cfm/listing/MTM Medication_Therapy_Management (last visited Sept. 19, 2011).

121. MIRIXA, http://www.mirixa.com/ (last visited Sept. 19, 2011). 
Intervention Program ("TIP ${ }^{\circledR}$ "). ${ }^{122}$ During a 2008 consensus meeting of pharmacy leaders to discuss the future path of MTM, one of the strategies identified to take MTM into the future was to "enable billing that is consistent among all payers and that is consistent with billing used by other health care providers." ${ }^{, 23}$ Last but certainly not least, pharmacy as a profession, much like nursing, must keep consistently researching and reporting the value of MTM in the literature to support the value of the return on investment. The Asheville Project with diabetes ${ }^{124}$ and asthma, ${ }^{125}$ the Diabetes Ten City Challenge, ${ }^{126}$ and the Fairview ten-year dataset from Minnesota, ${ }^{127}$ are excellent examples of datasets demonstrating the clinical and economic value of pharmacists providing MTM services. Over two million patients have accessed the benefits of MTM services thus far and have witnessed firsthand pharmacists providing health care services. ${ }^{128}$ Furthermore, CMS estimates that as many as one- fourth of Medicare Part D drug prescription plan patients were eligible for MTM services in 2010, and CMS is requiring Part D plans to expand. ${ }^{129}$ Plans currently offering MTM are seeing as much as $\$ 4.73$ for every dollar spent as the return on investment in MTM. ${ }^{130}$ Also, even some patients with chronic conditions are willing to pay for MTM services; one study demonstrated that patients were willing to pay on average $\$ 17.57$ for a MTM session. ${ }^{131}$ Through these continued three practices, there is no reason why lawmakers should not give pharmacists provider status at the federal and state levels, if the continued research, credentialing, and harmonization of MTM services continue. As said recently by an independent pharmacy owner:

Pharmacists have been filling and dispensing prescription medications, counseling patients (free of charge), and advising in the use of over-the-counter

122. Outcomes $®$ Detects One Million Drug Therapy Problems, BusINEss WIRE (Oct. 27, 2010), http://www.businesswire.com/news/home/20101027006938/en/Outcomes\%C2\% AE-Detects-Million-Drug-Therapy-Problems.

123. Marsha K. Millonig, Mapping the Route to Medication Therapy Management Documentation and Billing Standardization and Interoperability Within the Health Care System: Meeting Proceedings, 49 J. AM. Pharmacists Ass'N e41, e50 (2009).

124. Miall, Jr., supra note 101.

125. Bunting \& Cranor, supra note 100.

126. Fera et al., supra note 114.

127. Ramalho de Oliveira et al., supra note 93 (quoting CTRS. FOR MEDICARE \& Medicaid Servs., Medicare Part D Medication Therapy Management (MTM) Programs, available at http://www.cms.gov/PrescriptionDrugCovContra/Downloads/ MTMFactSheet.pdf).

128. Godwin, supra note 117.

129. Renee Frojo, As CMS Toughens MTM Regs, Plans Demand More ROI Data, AISHEALTH.COM (Oct. 19, 2010), http://aishealth.com/archive/ndbn100810-03.

130. Id.

131. Megan Friedrich et al., Patients' Needs and Interests in a Self-Pay Mediation Therapy Management Service, 50 J. AM. PHARMACISTS Ass'N 72 (2010). 
medications (free again) for years. However, it is the dispensing function that has been almost exclusively the main revenue generator for pharmacists .... We need to create and implement cognitive-based functions into pharmacy practice that are viable and reimbursable. $^{132}$

Some third-party health care insurers, like Blue Shield of California, see the value of MTM services and what a pharmacist can bring to the table for patients. Said regarding MTM services by Dr. Andrew Halpert, medical director at Blue Shield, "The pharmacists 'could do as well and better than a physician' for less money.",133

\section{The Medical Home and Collaborative Practice Agreements}

Although the concept of the medical home is not new to medicine, the concept of the addition of a pharmacist to the medical home team is a newer concept and increasingly of interest because of the medical home programs mandated by CMS in the new health care legislation. The idea or concept of the medical home originated in pediatric medicine, ${ }^{134}$ where the American Academy of Pediatrics described the model as "a central location for archiving a child's medical record," ${ }^{35}$ which also involves coordinating patient care, ${ }^{136}$ in the form of "accessible, continuous, comprehensive, family-centered, coordinated, compassionate, and culturally effective care." The model utilizes a team-based approach to a patient's care, in particular for patients being treated for multiple health conditions, with physicians, nurses, pharmacists, social workers, dieticians, and other healthcare providers. ${ }^{138}$ Pharmacists may be integrated into this model in one of three ways - either by contracting with the physician's group, by charging for MTM services incident to prescription dispensing, or being hired as a full-

132. Maria Young, Partnering with Pharmacists, PM360, Sept. 2010, at 38, 39, available at $\mathrm{http} / / / \mathrm{www} . \mathrm{pm} 360$ online.com/fl_0910 (last visited Sept. 15, 2011).

133. Reed Abelson, Pharmacists Take Larger Role on Health Team, N.Y. TimEs, Aug. 13, 2010, http://www.nytimes.com/2010/08/14/health/14pharmacist.html?emc=eta1.

134. Charles J. Homer et al., A Review of the Evidence for the Medical Home for Children with Special Health Care Needs, 122 PEDIATRICs e922, e922 (2008), available at http://www.pediatrics.org/cgi/content/full/122/4/e922.

135. Lisa A. Daigle \& Kristin Banek, Pharmacists' MTM Services Key to Health Care Homes' Success, AM. Soc'y Health-Sys. PhaRmacists 1, 2 (Mar. 2009), www.ashp.org/ DocLibrary/News/Health_Care_Home.pdf.

136. Id.

137. Id.

138. Id.; see also Marie Smith et al., Why Pharmacists Belong in the Medical Home, 29 HEALTH AFF. 906, 906 (2010) ("[Pharmacists] perform comprehensive therapy reviews of prescribed and self-care medications, resolve medication-related problems, optimize complex regimens, design adherence programs, and recommend cost-effective therapies. Pharmacists should play key roles as team members in medical homes."). 
time employee by the practice. ${ }^{139}$ Furthermore, pharmacists may contract with physicians under a "collaborative drug therapy management"140 ("CDTM") agreement in order to provide medication and health management programs. As of 2008, forty-five states allowed CDTM between doctors and pharmacists. ${ }^{141}$ CDTM is authorized at the state level by state boards of pharmacy, and typically utilizes practice protocols, which may or may not allow pharmacists to modify a patient's therapies, order laboratory tests, educate, monitor, and assess therapeutic responses, and actually administer medication. ${ }^{142}$ In Indiana, CDTM is only allowed in the institutional setting, such as the Veterans Health Administration ("VA") system, and the Indian Health Services ("IHS"). ${ }^{143}$ Under IHS, a grant gave pharmacists the opportunity to develop the Pharmacist Practitioner Program, which allowed pharmacists to provide drug therapy management along with physicians, and demonstrated positive results. ${ }^{144}$ However, Indiana is lagging behind over thirty other states, where CDTM is allowed in a variety of settings, beyond acute care and mental health facilities. ${ }^{145}$ There exists "considerable evidence that clinical pharmacy interventions reduced the frequency of drug-related problems in the elderly." model of the medical home, Geisinger Health System, found that by aggressively focusing on primary care and managing chronic diseases, the system realized $7 \%$ savings in costs and a " $20 \%$ reduction in hospital admissions." 147 However, while pharmacists have and continue to demonstrate their value in the medical home model, the increasing issue at hand is how pharmacists get paid for providing this health care. ${ }^{148}$ "[C]are in the outpatient setting and after hospital discharge is paid on a fee-for-service basis, and visits to pharmacists are not reimbursed in most states."149 It is difficult to justify hiring a pharmacist in a medical home without the ability to bill for and be reimbursed by insurance companies and Medicare, without pro-

139. Daigle \& Banek, supra note 135 , at 3 .

140. Id.

141. AM. Pharmacists Ass'N, Issue Brief: Collaborative Drug Therapy Management (Mar. 2008), http://www.pharmacist.com/AM/TemplateRedirect.cfm?template=/CM /ContentDisplay.cfm\&ContentID $=16882$.

142. Id.

143. Raymond W. Hammond et al., ACCP Position Statement: Collaborative Drug Therapy Management by Pharmacists-2003, 23 PHARMACOTHERAPY 1210, 1213 (2003), http://www.pharmacotherapy.org/pdf/free/Pharm2309_ACCP-TherMgmt.pdf (It is interesting to note that The Federal Food, Drug and Cosmetic Act ("FDC") of 1938 and DurhamHumphrey amendment of 1951 actually led to pharmacists being unable to prescribe drugs. Prior to this legislation, pharmacists could prescribe.).

144. Id.

145. AM. Pharmacists Ass'N, supra note 141.

146. David W. Bates, Role of Pharmacists in the Medical Home, 66 AM. J. HeAlthSYs. PHARMACY 1116, 1116 (2009).

147. Id. at 1117 .

148. Id. at 1116 .

149. Id. at 1117. 
vider status. In June 2008, the Medicare Payment Advisory Commission's Report to the Congress, Reforming the Delivery System, suggested that patient medication reviews should be managed with a pharmacist. ${ }^{150}$ However, who will pay for providing these services if pharmacists do not have the ability to bill as providers of health care?

Indiana, during the 2011 legislative session, has introduced House Bill No. 1111, which would expand collaborative practice from hospital settings to any setting where there exists a physician under protocol. ${ }^{151}$ This "drug therapy management" bill would allow pharmacists with physicians under protocol to adjust medication dosing. ${ }^{152}$ Indiana, along with five other states-Illinois, North Dakota, Nevada, Arizona, and New Hampshirerestricts drug therapy management practices. ${ }^{153}$ As of this writing, it is unknown whether H.B. 1111 in Indiana will receive a hearing by the House Public Health Committee. ${ }^{154}$ Currently, under Indiana Code Section 25-2616-1, hospitals and health facilities can authorize pharmacists via protocol only to adjust drug regimens for patients. ${ }^{155}$ Expanding collaborative practice from hospital-only settings between pharmacists and physicians to all potential practice settings would advance pharmacists in providing health care to patients and assisting with disease state management programs, in order to help keep rising health care costs from bankrupting the U.S. health care system.

\section{Emergency Preparedness and Response}

Last, but certainly not least, pharmacists can get involved in disaster/emergency preparedness and response teams. With the recent examples of natural disasters in Haiti and Chile internationally, Hurricane Katrina in the United States, and even the June 2008 flooding of mid-central and southern Indiana ${ }^{156}$ pharmacists can play a pivotal role in satisfying the higher demand for primary care during natural disasters. As stated by a physician in the Annals of Internal Medicine writing about response to disaster with health care professional students, "the need for primary care increased for the many persons deprived of appropriate housing and living in

150. Medicare Payment Advisory Comm'N, Report to the Congress: ReForming THE DELIVERY SYSTEM (2008), available at http://www.medpac.gov/documents/ jun08 entirereport.pdf. See also Daigle \& Kristin Banek, supra note 135, at 1.

151. H.B. 1111, 2011 Gen. Assemb. 1st Sess. (Ind. 2011).

152. E-mail from Mary Andritz, Dean, Butler University College of Pharmacy and Health Sciences, to Erin Albert, Assistant Professor, Butler University (Jan. 28, 2011, 01:39 EST) (on file with author).

153. Id.

154. Id.

155. IND. CODE. § 25-26-16-1 (2011).

156. ERIC R. RidDle, WATERSHED: SERVICE IN THE WAKe OF Disaster. (1st ed. 2009) (This book chronicles the flooding in June, 2008, in Columbus, Indiana. In Indiana during this flood, there were three disaster areas declared at the federal level.). 
dangerously unsanitary conditions due to the lack of drinking water, electricity, and safe food." 157

Internationally, "Pharmacists can contribute to ensure that the disaster victims have timely accessibility to medicinal supply in fulfilling their current practice responsibilities as well as expanded roles of first responder, triage, immunization, and first aid administration." 158 In the United States, some states are mandating that pharmacists have some specific continuing education in emergency preparedness; ${ }^{159}$ however, Indiana does not yet have this requirement for pharmacists.

Pharmacists who volunteered in Haiti described their work and challenges, including providing medications, dosing, finding alternative drugs when the first choice was not in stock, and determining drug dosing from medications unavailable in the United States, without assistance of traditional resources, such as the internet and/or computers. ${ }^{160}$ Pharmacists also can be members of Disaster Medical Assistance Teams ("DMATs"), and some who were U.S. DMAT members went to Haiti to help victims of the earthquake as well. ${ }^{161}$ The DMATs in the United States are now being deployed to natural disasters outside the United States. ${ }^{162}$ A DMAT member and emergency room pharmacist in Massachusetts, Shannon Manzi was deployed to Haiti and creatively helped with optimizing use of materials, such as syringes, that were not needed for normal use (insulin syringes), but instead figured out how to use them in administering morphine subcutaneously. ${ }^{163}$ She also helped translate French-made tetanus immune globulin for patients. 164 She also responded to all "codes"165 at the facility in which she was deployed. Pharmacists can currently work with or voluntarily sign up to serve DMATs, their own state boards of pharmacy, Metropolitan Medical Response Systems ("MMRS"), ${ }^{166}$ or with the U.S. Department of

157. Humberto Reyes, Students' Response to Disaster: A Lesson for Health Care Professional Schools, 153 ANN. INTERNAL MED., 658, 658 (2010).

158. INT'L PHARM. FED'N, FIP Statement of Professional Standards, The Role of the Pharmacist in Crisis Management: Including Manmade and Natural Disasters and Pandemics (Aug. 2006), http://www.fip.org/www/uploads/database_file.php?id=275\&table_id=.

159. The Univ. of Georgia Coll. of Pharm. Continuing Educ. \& OÚtreach, http://www.rxugace.com/emergency (last visited Feb. 14, 2011) (Website outlines the requirement in Georgia for pharmacists to complete at least 3 hours of continuing education in emergency preparedness.).

160. Campbell pharmacy graduates volunteer in Haiti field hospital, CAMPBELL UNIV., at 2 (May 24, 2010), http://www.campbell.edu/news/item/campbell-pharmacy-graduatesvolunteer-in-haiti-field-hospital.

161. Cheryl A. Thompson, Pharmacist's Out-of-the-Box Thinking Helps Haitian Earthquake Victims, AM. SoC'Y HeAlTh-Sys. PharmacisTs (Feb. 1, 2010), http:// www.ashp.org/menu/News/PharmacyNews/NewsArticle.aspx?id=3266.

162. Id. at 1 .

163. Id. at 2 .

164. Id.

165. Id. at 3 .

166. Laurie L. Briceland, Pharmacists and Emergency Preparedness, MEDSCAPE 
Health and Human Services as part of the Emergency System for Advance Registration of Volunteer Health Professionals ("ESAR-VHP"). ${ }^{167}$ Also, after the tragedy of $9 / 11$, pharmacy and public health leaders met to understand the issues facing emergency preparedness relative to the pharmaceutical supply chain - yet another way to have pharmacists better manage disaster recovery and better manage drug shortages. ${ }^{168}$ Emergency management and preparedness are yet another way that pharmacists can provide health care in times of need, and in particular, primary care, to patients who may not otherwise receive care. Through these various organizations, pharmacists can and have volunteered their time and talent to patients in need and therefore are truly providing care already during natural and human disasters.

\section{B. Pros and Cons of Pharmacists as Legal Health Care Providers}

All new ideas come with skepticism and controversy. There are arguments against pharmacists becoming legal health care providers under the Social Security Act federally, and at the state level, including Indiana. There is also strong support of pharmacists as legal health care providers. Both viewpoints are detailed below.

\section{Physicians' and Professional Organizations' Opinions on Pharma-} cists as Legal Health Care Providers

There is resistance on the part of major physician professional societies for allowing other health care professionals to provide health care. The American Academy of Family Physicians ("AAFP") "believes that only licensed doctors of medicine, osteopathy, dentistry, and podiatry should have the statutory authority to prescribe drugs for human consumption"169 and "[p]harmacists should not alter a prescription written by a physician, except in an integrated practice supervised by a physician or when permitted by state law." However, AAFP goes on to state in a position paper on Pharmacists that in a collaborative setting,

Patients treated in a pharmacist-managed clinic had better anticoagulation control, fewer bleeding and thrombotic complications, fewer hospitalizations and

ToDAY (Oct. 14, 2002), http://www.medscape.com/viewarticle/442444.

167. U.S. DePT. OF HEAlTH \& HUMAN SERVS., THE EMERGENCY SYSTEM FOR ADVANCE Registration of Volunteer Health Professionals: About ESAR-VHP, FAQs (2011), available at $\mathrm{http}: / / \mathrm{www}$.phe.gov/esarvhp/pages/faqs.aspx.

168. Summary of the executive session on emergency preparedness and the pharmaceutical supply chain, 59 AM. J. HEALTH-SYs. PHARMACY 247 (2002).

169. Drugs, Prescribing - AAFP Policies, Am. ACAD. Fam. Physicians, http:// www.aafp.org/online/en/home/policy/policies/d/prescribing.html (last visited Dec. 28, 2011). 
emergency room visits, and lower health care costs compared to newly anticoagulated patients treated in the standard manner. Collaborative programs have demonstrated success in other areas, including hyperlipidemia, asthma, diabetes, and hypertension. ${ }^{170}$

The American Medical Association ("AMA") released the $A M A$ Scope of Practice Data Series: Compendium on Pharmacists in September 2009 to policymakers. ${ }^{171}$ While the report was not yet publicly released, the document was released to leaders of several pharmacy organizations. In a letter signed by leaders of the American Pharmacists Association, American Association of Colleges of Pharmacy, the American College of Clinical Pharmacy and four other national pharmacy organizations dated April 16, 2010 to Dr. Michael Maves, CEO of the American Medical Association, pharmacy leaders voiced "serious concerns about the portrayal within the document of pharmacists' scope of practice, the provision of collaborative drug therapy management (CDTM) services, and the education and training of pharmacists."172 The letter goes on to state, "The suggestion in the document that the evolving scope of practice of pharmacists serves primarily to 'compensate' for increased automation and utilization of pharmacy technicians is simply wrong."173 The drafters of the response letter suggested that the inaccuracies be corrected, and concluded that, "pharmacists are filling roles today that were largely unmet and that support the health care team in a patient centered model."174 Interestingly, the AMA Scope of Practice Data Series: Pharmacists has yet to be released to the public. In response to the letter, President of the American Pharmacists Association, Thomas Menighan, responded in a follow-up publication that,

we [pharmacists] continue to get "good press" from many nonpharmacist organizations that see the value of pharmacists as medication coaches in collaboration with other healthcare professionals and as part of the medical or health home. Organizations such as AARP, the Patient-Centered Primary Care Collaborative, the Joint Commission, the Association of Academic Health Centers, and the Institute of Medicine

170. AM. ACAD. FAM. Physicians, Pharmacists (Position PAPER) (2006), available at http://www.aafp.org/online/en/home/policy/policies/p/pharmacistspositionpaper.html.

171. Ted Agres, AMA Seeks Limits to Pharmacists' Scope of Practice, 37 PHARMACY PrAC. NEwS 5 (May 2010), available at http://www.pharmacypracticenews.com /ViewArticle.aspx?d_id=51\&a_id=15162.

172. Letter from Thomas E. Menighan, Pres. Am. Pharmacists Ass'n et al. to Michael D. Maves, CEO, Am. Medical Ass'n (Apr. 16, 2010) (on file with author).

173. Id.

174. Id. 
have all recognized contributions that pharmacists can make on the healthcare team. ${ }^{175}$

Of course, another way to fix the primary care doctor shortage would be to offer more residencies and increase primary care providers' pay; however, "there's resistance to these steps because of their costs," to Kaiser Health News in a report on health bills in Congress not fixing the primary care shortages. Legislative attempts at expanding primary care training are not feasible because of a $\$ 10$ billion price tag over ten years. ${ }^{177}$ Who, then, will fill the primary care void?

\section{Pharmacist Professional Societies and Support of Pharmacists as Legal Providers}

Last, there are several organizations, both in and around pharmacy, that support the concept of pharmacists increasing their role on health care teams. Donald Berwick, physician and head of CMS, "strongly agreed that meds are a critical issue and pharmacy is a critical player," at a public conference on Community-Based Care sponsored by CMS. ${ }^{178}$ Furthermore, AARP and Walgreens partnered on the "AARP/Walgreens Wellness Tour" to recently surpass their two millionth health screening. ${ }^{179}$ The tour began in April 2009 and health screenings have been free to patients in "more than 3,000 underserved communities throughout the United States and Puerto Rico." 180 Stated A. Barry Rand, CEO of AARP, of the tour, "These screenings [cholesterol levels, blood pressure, bone density, glucose, waist circumference, and body mass index] by Walgreens will go a long way in increasing the chances for early detection of chronic disease and other potential health problems."181 Even as far back as 2002, the federal Health Resources and Services Administration ("HRSA") partnered via contract with the American Pharmacists Association ("APhA") to establish the

175. Thomas E. Menighan, Pharmacy response to the "AMA Scope of Practice Data Series: Pharmacists", DRUG TOPICS (June 15, 2010), available at http://drugtopics. modernmedicine.com/drugtopics/Associations/Pharmacy-response-to-the-AMA-Scope-ofPractice-Dat/ArticleStandard/Article/detail/673895.

176. Phil Galewitz, Health Bills in Congress Won't Fix Doctor Shortage, KAISER Health News (Oct. 13, 2009), http://www.kaiserhealthnews.org/Stories/2009/October/12/ primary-care-doctor-shortage.aspx.

177. Id.

178. Thomas Menighan, Berwick says pharmacy central to health care team, AM. PhARMACISTS Ass'N, CEO BloG (Dec. 3, 2010), http://blog.pharmacist.com/tmenighan/ index.php/2010/12/03/berwick-says-pharmacy-central-to-health-care-team/.

179. "AARP/Walgreens Wellness Tour" To Administer Two Millionth Free Health Screening, PRNEWSWIRE, Nov. 12, 2010, available at http://multivu.prnewswire.com/ $\mathrm{mnr} /$ walgreens/47199/.

180. Id.

181. Id. 
Pharmacy Services Support Center ("PSSC"), which "was created to address the needs of pharmacists associated with HRSA grant projects and eligible community health centers to ensure patients have access to pharmaceuticals, medication management, and pharmacy services as part of their total health care."182 Major patient organizations (AARP), government agencies such as HRSA, and of course pharmacy organizations - both forprofit (Walgreens) and not-for-profit (APhA)-all see the value in pharmacists playing a role in providing health care to patients. Why not then make pharmacists legal health care providers?

\section{Liability and Provider Status}

As the old adage goes, with privilege comes responsibility. Pharmacists, if given provider status under the eyes of both the federal law as well as Indiana state law, must take the privilege along with the heightened level of responsibility-including possible liability. For example, courts in the past have generally held pharmacists and pharmacies strictly liable for assurance "of the safety of a manufactured drug and would impose on the retail druggist the obligation to test, at its own expense, new drugs. The costs to society, which needs and values the pharmaceutical products sold by druggists, would be unduly high." 183 However, courts in the past have also taken pharmacists out of the equation and released them from a duty to warn relative to drug side effects and safety; ${ }^{184}$ but would this change if pharmacists were considered a health care provider under federal law and/or Indiana state medical malpractice law?

If pharmacists were included under Indiana medical malpractice laws, liability may decrease, rather than increase, for pharmacists. As earlier stated, there is a two-year statutory window for bringing medical malpractice claims on "providers" in Indiana; however, technically, because pharmacists are not considered "providers" under that statute, they in theory have no time limits for claims against them.

182. Author unknown, The Pharmacist as the Primary Care Provider for the Medically Underserved, 43 J. AM. PhaRmacists Ass'N S52, S52 n.5 (2003).

183. Ramierz v. Richardson-Merrell, Inc., 628 F.Supp. 85, 87 (E.D. Pa. 1986); see also Jeffery J. Carlson, Today's Pharmacist: A Seller of Products or a Provider of Services?, FoR THE DEFENSE, Nov. 1987, at 15.

184. Ramierz, 628 F.Supp. at 87; see also Carlson, supra note 183, at 21 (This paper discussed Ramierz, in which the court stated, "To impose a duty to warn on the pharmacist . . . would be to place the pharmacist between the physician ... and the patient. Such interference in the patient-physician relationship can only do more harm than good."). See also Ingram v. Hook's Drugs, Inc., 476 N.E.2d 881, 887 (Ind. Ct. App. 1985) ("The injection of a third-party in the form of a pharmacist into the physician-patient relationship could undercut the effectiveness of the ongoing medical treatment."). 


\section{CONCLUSION}

Pharmacists are already giving care to patients in expanded means, beyond mere dispensing of medications. Through longer and more thorough education, board certifications, and additional training to provide immunizations, medication therapy management, and emergency/disaster relief, pharmacists are becoming more knowledgeable about primary care than ever in order to fill in the gaps where the needs of the rural, urban, and underserved populations are not currently being met. Now, more than any time in U.S. history, the people need affordable solutions to their health care needs, and pharmacists are fulfilling those needs in unique and creative ways. The question that remains is: will payers, who are ultimately the federal government, state governments, and employers, finally recognize pharmacists as true health care providers? If pharmacists are already doing the work, they should have already earned provider status. It is time for the law-both federal and state-to match reality and make pharmacists legal health care providers.

\section{ADDENDUM}

Three key events occurred in the past year relative to the movement toward pharmacists becoming legal health care providers. First, on February 3, 2011, the Medication Therapy Management Empowerment Act of 2011, or S. 274 was introduced by Senator Kay Hagan of North Carolina with 15 cosponsors. ${ }^{185}$ The bill notes that the cost of improperly taking medication for the U.S. is $\$ 290$ billion annually, and also cites the Asheville Project. ${ }^{186}$ The bill essentially proposes improvements in Part D MTM programs, including increased access for patients to MTM, expansion to other chronic diseases, and performance-based incentive payments for better medication adherence outcomes. ${ }^{187}$ The bill was read twice and referred to the Committee on Finance and currently sits in committee. ${ }^{188}$

Second, a report from the U.S. Public Health Service - Office of the Chief Pharmacist was written to the U.S. Surgeon General. ${ }^{189}$ In this report, pharmacists outlined that via evidence-based outcomes, pharmacists are,

185. S. 274, 112th Cong. (2011).

186. Id. at $\S 2(3),(6)$.

187. Id. \& 3 .

188. Email from Whitney Zatzkin, Policy and Advocacy Manager, The American Association of Colleges of Pharmacy, to Erin Albert, Assistant Professor of Pharmacy, Butler University (Jan. 12, 2012, 5:21 PM) (on file with the author).

189. Scott Gilberson et. al, Office of the Chief Pharmacist, U.S. Pub. Health Serv., Improving Patient and Health System Outcomes tHrough AdVanced Pharmacy Practice. A Report to the U.S. SURGeon General, Dec. 2011, available at http://www.usphs.gov/corpslinks/pharmacy/comms/pdf/2011AdvancedPharmacyPracticeRe porttotheUSSG.pdf. 
"already integrated into primary care as health care providers. Pharmacists unquestionably deliver patient care services in a variety of practice settings through collaborative practice with physicians or as part of a health care team." 190 The report also states, "pharmacists may be the only health professionals (who manage disease through medications and provide other patient care services) who are not recognized in national health policy as health care providers or practitioners." ${ }^{\prime 191}$ One of the leading objectives of this report was to "[o]btain advocacy from the U.S. Surgeon General to recognize pharmacists, who manage disease and deliver many patient care services, as health care providers. One such action is advocate to amend the Social Security Act to include pharmacists among health care professionals classified as "health care providers." 192

The U.S. Surgeon General, Dr. Regina Benjamin, clearly read the report, and on December 14, 2011, issued a letter stating that the report provided, "a thorough discussion of the comprehensive patient care services that pharmacists are currently providing."193 The letter further stated, that, "Recognition of pharmacists as health care providers, clinicians and an essential part of the health care team is appropriate given the level of care they provide in many health care settings."194 Thus, the perfect storm for pharmacists as providers under the Social Security Act is documented, imminent and palpable.

190. Id. at 7 .

191. Id. at 8 (emphasis added).

192. Id. at 10 (emphasis added).

193. Letter from Regina Benjamin, MD, MBA, U.S. Surgeon General, to RADM Scott Giberson, Chief Professional Officer, Pharmacy - U.S. Assistant Surgeon General (Dec. 14, 2011), available at http://www.usphs.gov/corpslinks/pharmacy/comms/pdf/2011Support LetterFromUSSG.pdf.

194. Id. at 2 . 